\title{
O Incidente de Resolução de Demandas Repetitivas: uma análise deste instrumento processual no Regimento Interno do Tribunal de Justiça do Estado da Bahia.
}

Resumo: O Novo Código de Processo Civil inseriu o Incidente de Resolução de Demandas Repetitivas (IRDR) no ordenamento jurídico brasileiro e este instituto consiste numa tentativa de fixar tese sobre uma determinada controvérsia, baseada nos processos repetitivos existentes em tribunais. Assim, o presente estudo tem como objetivos principais discutir os aspectos atrelados ao Incidente de Resolução de Demandas Repetitivas, desvelando fatores históricos que o impulsionaram e também a sua funcionalidade e aplicabilidade a partir das suas normas codificadas e instrumentalizadas no Regimento Interno do Tribunal de Justiça da Bahia (RITJBA). A metodologia é pautada na revisão bibliográfica da doutrina processual civil, no procedimento de análise e comentário de textos legais e na consulta ao banco de dados do Núcleo de Gerenciamento de Precedentes do Tribunal de Justiça do Estado da Bahia. A pesquisa aponta que a regulamentação do IRDR pelo TJBA é paradigmática e que a fixação de teses a partir do julgamento desses incidentes agilizou a resolução de demandas massificadas.

Palavras-chave: Ação coletiva. Precedente obrigatório. Incidente de Resolução de Demandas Repetitivas.

\section{The Repetitive Claims Resolution Incident: an analysis of this procedural tool in the Internal Rules of the Court of Justice of Bahia State.}

\begin{abstract}
The New Code of Civil Procedure inserted the Repetitive Claims Resolution Incident into Brazilian legal system and this institute is an attempt to establish a thesis on a particular controversy, based on the repetitive demands there are processed in the courts. Thus, the present study has as main objective to discuss the aspects linked to the Repetitive Claims Resolution Incident, unveiling historical factors that generated it; its functionality and applicability based on Procedure Code and the predicted rules from the Internal Regulations of the Court of Justice of Bahia State. The methodology is based on the bibliographic review of civil procedural doctrine, analysis and comment of the legal text, and consults of database of the Precedent Management Center of the Court of Justice of the State of Bahia. The research points out that the regulation of the RCRI by the TJBA is paradigmatic and that the establishment of theses based on the judgment of these incidents speeded up the resolution of massified claims.
\end{abstract}

Key words: Collective action. Compulsory precedent. Repetitive Claims Resolution Incident

\footnotetext{
${ }^{1}$ Mestrando no Programa de Pós-graduação em Direito da Universidade Federal da Bahia (PPGD UFBA). Especialista em Direito Processual Civil pela Faculdade Baiana de Direito. Graduado em Direito pela Universidade Estadual do Sudoeste da Bahia. Advogado. E-mail: lucas_alveslobo@hotmail.com.
} 


\section{Introdução}

Diante de um quadro nacional de massificação de demandas repetitivas o legislador ordinário, ao editar o Novo Código de Processo Civil (CPC/2015), previu a possibilidade de solucionar esse problema por meio da instauração de um incidente processual, "aglutinador de ações originalmente singulares ${ }^{\prime 2}$, que fosse hábil a instrumentalizar uma solução por intermédio da formulação de uma tese padrão. Essa tese seria, então, aplicada a todos os processos que versassem sobre determinada questão comum, produto de um profundo debate travado no curso da instrução processual do incidente.

Com inspiração em sistemas de resoluções de causas repetitivas encontrados no direito estrangeiro, o Incidente de Resolução de Demandas Repetitivas (IRDR) é uma inovação proporcionada pelo CPC/2015, que visa estabelecer uma forma efetiva de agilizar a resolução de causas que massificam e dão morosidade ao judiciário brasileiro.

O presente estudo pretende apresentar o IRDR, seu conceito, seus pressupostos processuais, além de fazer uma breve síntese do contexto jurídico que provocou o surgimento das demandas repetitivas que deram origem ao referido instituto. Especificadamente, esse trabalho objetiva apresentar uma análise do tratamento que o Tribunal de Justiça do Estado da Bahia (RITJBA) destinou ao IRDR em seu regimento interno, ao tempo em que aponta a importância dessa novidade procedimental e o didatismo regimental.

O conjunto metodológico utilizado para compor este estudo perpassa pelo método dedutivo. Diante dos objetivos propostos, essa pesquisa é explicativa; de abordagem qualitativa e cujo procedimento técnico é bibliográfico e documental, tendo como fontes livros de doutrina processual civil, artigos, monografias, dissertações, teses, enunciados processuais e a legislação correlata.

Essa pesquisa é motivada pela proposição de um debate acerca de um instituto processual novo e sobre a importância que assumem os regimentos internos de tribunais na tarefa de instrumentalizar a aplicabilidade do IRDR.

\section{Antecedentes históricos e sociais: aspectos gerais do Incidente de Resolução de} Demandas Repetitivas

O fenômeno da globalização, marca característica do final do último século, fomentou a dinamização do fluxo de informações e da comunicação como um todo, de modo a

${ }^{2}$ De acordo com Humberto Theodoro Júnior, é o tipo de tutela judicial coletiva por meio do qual uma só decisão se estende às diversas causa individuais que possuem objetos iguais. 
torná-las fenômenos caracterizados pela instantaneidade. Uma característica marcante da sociedade atual é a sua complexidade. Esse fenômeno é refletido nas relações jurídicas e há, sem dúvidas, um perceptível crescimento na quantidade de litígios e poucas perspectivas de contenção dessa litigiosidade de massa, que é decorrente da dinâmica social construída a partir do final do último século (BASTOS, 2012, p. 16).

Há alguns fatores que contribuem para o aumento constante de litígios em massa, a exemplo da ampliação dos meios de comunicação social, do aumento da consciência jurídica dos cidadãos, do advento de novas tecnologias e da oferta de novos produtos, aumentando as necessidades do consumo humano, a fúria legislativa, entre outros (DIDIER JR.; CUNHA, 2017, pp. 666-667). É notável a existência de um liame entre as transformações sociais observadas no século passado e a existência de conflitos judicias. No Brasil, esse fenômeno também é perceptível a partir do momento em que a democratização, difusão da informação e o apelo ao consumo fizeram com que os indivíduos se percebessem como titulares de inúmeros direitos, inclusive o de acionar o judiciário para ter suas pretensões atendidas (FREITAS, 2015, p.13).

Deve-se considerar também que a estrutura do Poder Judiciário não foi pensada e nem está totalmente organizada para receber enormes quantidades de processos repetitivos, bem como dar-lhes a solução adequada. Inexistem recursos suficientes e bem empregados para resolver o abarrotamento dos fóruns e tribunais em todo o país, sendo deficiente a análise e o tratamento do fenômeno da litigância de massa também sob a dimensão dos processos tomados em seu conjunto (TEMER, 2017, p. 33). Nesse mesmo sentido:

Do ponto de vista da efetividade, o volume absurdo de processos gerou, acima de tudo, grande morosidade para sua condução, decorrente do número limitado de servidores, juízes e recursos financeiros para o atendimento da demanda. Somadas as causas repetitivas em todo país, o número chega a casa dos milhões. O fato de elas serem analisadas individualmente - e não em bloco - atenta seriamente contra a economia processual, valor inserido no complexo valorativo da efetividade (AMARAL, 2011 apud TEMER, 2017, p. 33).

Esse movimento de busca pela tutela jurídica do Estado pode ser visto como consequência do processo de democratização do país, sobretudo se atentarmos ao fato de que houve um crescimento das demandas protocoladas no Supremo Tribunal Federal (STF), após o advento da Constituição Federal de 1988. Além de fruto do processo de democratização do país, provocado pela democratização do acesso à justiça, a busca pelo Estado-juiz para fins de soluções de conflitos é decorrência do fortalecimento dos órgãos jurisdicionais (MENDES; TEMER, 2015, p.2).

Fenômeno interessante se percebe também no mesmo período em que se observa o crescimento das demandas ajuizadas no país - as demandas passaram a ser isomórficas. Essas 
demandas isomórficas ou repetitivas massificadas podem ser caracterizadas pela identidade em tese e não em concreto, da causa de pedir e do pedido, associada à repetição em larga escala constituindo um cenário próprio de litigiosidade de massa (MENDES; TEMER, 2015, p.2).

Todo esse crescimento das demandas de massa exigiu do legislador a produção de normas processuais que implementassem mecanismos de resolução de conflitos judiciais em grande escala, mediante o desenvolvimento de instrumentos processuais que se ajustassem ao contexto. O que se exigiu da produção normativa processual e a elaboração de técnicas processuais diferenciadas.

O direito processual brasileiro desenvolveu-se a partir da análise de litígios individuais. Em decorrência lógica, a legislação processual, tradicionalmente, tutela o processo individual (DIDIER JR.; CUNHA, 2017, p. 666). Nota-se uma incapacidade do processo civil clássico, fundado na resolução de demandas individuais, de resolver demandas isomórficas massificadas.

Podemos apontar, dentre alguns instrumentos processuais existentes no

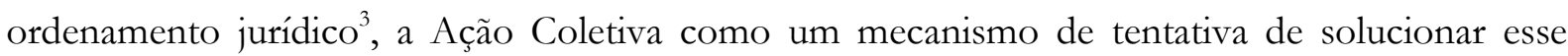
problema. Contudo, é preciso que se afirme que Ação Coletiva em sua integralidade não resolve a problemática em apreço, sobretudo em razão do sistema brasileiro de extensão dos efeitos da coisa julgada secundum eventum litis, da possibilidade de ajuizamento concomitante de ações individuais e da restrita legitimação ativa (MENDES; TEMER, 2015, p.2).

O Incidente de Resolução de Demandas Repetitivas está previsto no novo Código de Processo Civil do art. 976 ao art. 987 e se apresenta como uma inovadora técnica processual que foi desenvolvida com o intuito de resolver ou tentar solucionar a questão da litigiosidade repetitiva. O incidente é uma das grandes apostas do novo diploma processual cujo objetivo é firmar uma tese jurídica única e aplicável a todos os casos repetitivos (MENDES; TEMER, 2015, p. 1).

Diante da incapacidade das ações coletivas de tutelarem com efetividade a questão da resolução de demandas isomórficas e massificadas, o legislador processual propõe com a inserção de um novo instituto processual que solucione de modo mais eficaz a problemática posta.

\footnotetext{
${ }^{3}$ A proteção normativa a direitos coletivos passou a ocorrer no ordenamento brasileiro sobretudo a partir de 1965 , com a disciplina da Lei da Ação Popular (Lei 4.717), que, embora já fosse prevista desde a Constituição de 1934, não tinha efetiva aplicação. O sistema de proteção coletiva foi fortalecido pela Lei da Ação Civil Pública (Lei 7.347/85) e, em seguida, a Constituição de 1988 ampliou a gama de direitos e garantias metaindividuais e o Código de Defesa do Consumidor (Lei 8.078/1990) aperfeiçoou os meios processuais para tutelá-los, consagrando-se um microssistema de proteção coletiva de direitos (TEMER, 2015, p. 34).
} 
IRDR é instituto processual que encontra pares no direito comparado, afinal a litigiosidade repetitiva não é um fenômeno isolado no âmbito da justiça brasileira. Esse mecanismo unificador ora instituído no ordenamento jurídico pátrio encontra precedentes no direito alemão, com o Musterverfahrem, no direito inglês com o Group Litigation e na Corte Europeia de Direitos Humanos com o Pilot-Judgment Procedure (THEODORO JÚNIOR, 2017, p. 921).

O IRDR pode ser suscitado no âmbito dos tribunais de justiça e tribunais regionais, cujo objetivo é a elaboração de uma tese que uniformize o entendimento do tribunal sobre determinada questão levada à sua apreciação. Esse incidente consiste numa técnica de processamento de questões repetitivas, mediante seleção de casos sobre os quais o tribunal irá produzir uma série de procedimentos, de modo que, ao final do seu trâmite, seja fixada uma tese jurídica, que será utilizada posteriormente na solução dos demais casos que possuam as mesmas questões de direito do caso que deu origem ao entendimento jurisprudencial, que foi produto do IRDR (TEMER, 2017, p. 39).

Cabe explicar o procedimento do IRDR em linhas gerais, para fins de entendimento de sua finalidade e melhor compreensão, consoante exposição no subtópico seguinte.

\section{O procedimento do IRDR}

Este incidente está previsto no CPC/2015, dos artigos 976 ao 987. O IRDR será suscitado pelo juiz ou relator, por ofício, pelas partes, Ministério Público e Defensoria Pública, por meio de petição. O ofício ou petição será dirigido ao presidente do tribunal competente (art. 977). Após a sua distribuição, o órgão colegiado regimentalmente designado, fará o juízo de admissibilidade do incidente (art. 981). Não sendo admitido, o incidente será extinto, do contrário, outras medidas podem ser tomadas, que passamos a expor.

Após a admissão do incidente, serão suspensos os processos pendentes, individuais ou coletivos que tramitem no estado ou região de jurisdição do tribunal (art. 982, I). A partir de então, o relator do incidente poderá requisitar informações a órgãos em cujo juízo tramita o processo no qual se discute o objeto do incidente (art. 982, II). Além dessa providência, o relator intimará o Ministério Público para se manifestar em 15 dias (art. 982, III). Poderá também o relator possibilitar às partes a juntada de documentos e de requerimento de diligências (art. 983), bem como possibilitar a realização de audiência pública a fim de elucidar questões atinentes ao caso $\left(\right.$ art. $\left.983, \$ 1^{\circ}\right)$.

Realizada a instrução do incidente, o relator solicitará dia para julgar o IRDR (art. $\left.983, \Omega 2^{\circ}\right)$. O julgamento do incidente resultará numa tese jurídica que será aplicada a todos os processos individuais ou coletivos que versem sobre idêntica questão de direito e também aos 
casos futuros (art. 985, I e II). Por fim, caberá recurso especial ou extraordinário, com efeito suspensivo e presunção de repercussão geral, da questão constitucional discutida (art. 987). Há também, frise-se, a possibilidade de revisão da tese jurídica fixada no incidente (art. 986).

\section{O IRDR no Regimento Interno do TJBA}

O IRDR, como já explicado, consiste numa nova técnica processual destinada a solucionar litígios repetitivos de massa. Entretanto, alguns aspectos procedimentais não foram esmiuçados pelo CPC/2015. Não há no referido código minuciosa explicação de como proceder ao tramite do incidente, coube ao dispositivo legal apenas traçar diretrizes gerais sem especificar o procedimento a ser seguido no ambiente interno dos tribunais, após a acolhida do incidente pelo órgão respectivo do tribunal, no qual ele seja suscitado.

É decorrência lógica da não especificidade do código ao tratar do tema que fique a cargo dos regimentos internos dos tribunais a devida complementação da disposição processual codificada. O regimento interno deve funcionar como um instrumento de integração da norma processual, ou nos exatos dizeres de Didier Jr. e Temer (2016, p.2), "preencher a lacuna da legislação processual". Aos tribunais, inclusive, cabe a tarefa de inovar, dentro das possibilidades estabelecidas pelo ordenamento jurídico, em relação ao texto legal, de modo a organizar e viabilizar o trâmite do incidente. Com o referido entendimento:

[...] talvez por se tratar de instituto sem correspondente na legislação processual revogada, relevantes aspectos não foram disciplinados pelo Código, notadamente os que dizem respeito ao procedimento a ser adotado logo após o pedido ou ofício de instauração e a decisão de admissão do incidente. (DIDIER JR.; TEMER 2016, p.1).

Nesse sentido, o TJBA, a partir da Emenda Regimental 01/2016, incluiu uma seção destinada a disciplinar o Incidente de Resolução de Demandas Repetitivas e o Incidente de Assunção de Competência em seu regimento interno. A seguir, passa-se a analisar o instituto processual em comento, cujo tratamento encontra-se positivado do art. 218 ao art. 226 do RITJBA $^{4}$, de modo a evidenciar similitudes e complementariedades entre o regimento e o CPC/2015.

$\mathrm{O}$ art. 218 confirma a relação de complementariedade do regimento com o CPC/2015, precisamente ao prescrever que "o incidente de resolução de demandas repetitivas e o incidente de assunção de competência serão processados de acordo com as normas decorrentes

4 O Regimento Interno do Tribunal de Justiça do Estado da Bahia está disponível em: http://www5.tjba.jus.br/portal/wp-content/uploads/2019/01/REGIMENTO-INTERNO-ATUALIZADO-EM10012019.pdf 
do Código de Processo Civil e deste regimento". Reforçando o seu caráter instrutivo, o regimento ainda traz no parágrafo único desse mesmo artigo que os incidentes elencados no caput "têm por objeto a solução de questão de direito material ou processual".

O dispositivo seguinte, art. 219, possui um caráter doutrinário bem explícito. Ele elucida o objeto do IRDR de forma bastante clara ao ditar que o incidente de resolução de demandas repetitivas tem por objeto a solução de questão de direito que se repita em diversos processos individuais ou coletivos, quando houver risco de ofensa à isonomia e à segurança jurídica.

Os doze parágrafos desse artigo instrumentalizam diversos pontos que o Código não fez. Nesses dispositivos e seus incisos está disposta toda a ritualística do incidente dentro do ambiente do órgão do tribunal que tem a competência regimental para julgá-lo. Desde a autuação até a disponibilização dos autos processuais para consulta pública na rede mundial de computadores, passando pela descrição do papel do relator e demais pormenores. $\mathrm{O} \int 1^{\circ}$ apenas reproduz o que consta no art. 977 do CPC/2015, sem maiores destrinches, vez que esse parágrafo apenas dispôs acerca do direcionamento do pedido de instauração do incidente, bem como o instrumento processual hábil a fazê-lo.

$\mathrm{O} \ 2^{\circ}$, no entanto, vai além do texto do Código ao esclarecer os poderes do relator na escolha do caso representativo do incidente e cabe salientar que essa é uma das questões mais sensíveis no que diz respeito ao IRDR, pois se devem privilegiar casos em que se verifiquem pluralidade de perspectivas argumentativas, sobretudo, tendo-se em mente que um dos escopos do IRDR, em sua concepção original, é prestigiar a isonomia e segurança jurídica, que se consubstanciam, também, a partir desse pluralismo de perspectivas.

A seleção das causas que representarão o caso requer parâmetros quantitativos e qualitativos. Cabe ao tribunal escolher mais de um processo repetitivo e, de acordo com o art. 1.036, $\iint 1^{\circ}$ e $5^{\circ}$ do $C P C$, devem ser selecionados dois ou mais casos que representem bem a questão controvertida. Esse parâmetro quantitativo é decorrência do microssistema de resolução de casos repetitivos. O parâmetro qualitativo consiste na escolha do processo que seja admissível e contenha argumentação abrangente, vide art. 1.036, \ $6^{\circ}$, CPC. Embora esse seja um dispositivo pertinente aos recursos repetitivos, pode ser aplicado também ao IRDR igualmente pela força do microssistema de julgamento de casos repetitivos (DIDIER JR.; CUNHA, 2017, pp. 703-704). Nesse sentido:

[...] é preciso destacar que o relator não fica vinculado (i) ao processo de onde surja o pedido ou ofício para instauração do IRDR; (ii) à escolha realizada pela presidência do tribunal (em se admitindo que haverá tal escolha), o que ocorre também da aplicação do art. 1.036, S $4^{\circ}$ do CPC/2015 (LGL \2015\1656) ao IRDR, havendo, portanto, ampla margem de atuação do relator, que poderá selecionar os processos representativos (DIDIER JR.; TEMER, 2016, p.4). 
Caso haja desistência ou abandono da causa que fundamente o IRDR, mesmo que o Ministério Público possa assumir a titularidade do incidente conforme estabelece o art. 976, $\ 2^{\circ}$, nada impede que o relator possa fazer uma nova escolha de casos representativos (vez que ele pode selecionar duas ou mais causas), quando tenha por objetivo ampliar a discussão sobre a questão jurídica (TEMER, 2017, p.156). A referência que o $\$ 2^{\circ}$ do art. 219 do RITJBA faz ao disposto no parágrafo segundo do art. 1036 do CPC em tudo tem a ver com o fato de se aplicar ao IRDR, regras contidas em outros artigos do CPC/2015 que não somente aquelas que regulamentam o incidente. Isso ocorre em virtude da existência do que a doutrina e a legislação processual chamam de microssistema de gestão e julgamento de casos repetitivos que é composto pelas normas que regulam o IRDR e os recursos repetitivos, que possuem a finalidade de escolher, pelo menos, dois processos para discussão e decisão, sobrestando-se os demais que ficam à espera da decisão paradigma (DIDIER JR.; CUNHA, 2017, p. 676).

Outra interessante disciplina tratada didaticamente no RITJBA que excede o que foi disposto no CPC/2015 diz respeito ao destino de eventuais novas tentativas de se instaurar incidentes cujos temas já são objeto de IRDR. Segundo o $\int 3^{\circ}$ do art. 219, novos pedidos que envolvam a mesma questão de direito serão rejeitados e devolvidos aos remetentes, para que eles, querendo, possam tomar ciência da existência de incidente, abordando a mesma temática pretendida e, assim entendendo conveniente, ingressar no feito como interventores.

Essa possibilidade de participação de interventores no incidente associa-se com a abertura à participação e à contribuição com informações para o debate que precede a fixação da tese (DIDIER JR.; TEMER, 2016, p.4).

Os $\iint 4^{\circ}$ e $5^{\circ}$ do art. 219 regulam o destino que o incidente terá ao chegar ao tribunal. $\mathrm{Na}$ hipótese da causa que der origem ao IRDR ser proveniente de recurso, remessa necessária ou processo de competência originária do Tribunal, caberá ao relator desses a relatoria do incidente por prevenção. O recurso, remessa ou processo originário deverão ficar apensos aos autos do incidente de modo que ambos sejam julgados (inteligência do CPC/2015, art. 978, parágrafo único). $\mathrm{Na}$ hipótese de a causa escolhida ser alheia ao órgão, será feito um sorteio entre os membros efetivos para que seja, então, atribuída a um deles a relatoria do incidente.

Os $\iint 6^{\circ}$ e $7^{\circ}$ do art. 219 regulam o que deve ser feito após a escolha do caso representativo do incidente. O relator deverá submetê-lo ao órgão colegiado responsável pelo julgamento, de modo que este possa realizar o juízo de admissibilidade do IRDR. Não sendo o incidente admitido e lavrado o respectivo acórdão, os autos permanecerão arquivados no Tribunal. 
Admitido o IRDR, caberá ao relator proferir o despacho de organização do incidente. Essa decisão corresponde a uma formalização do que foi decidido pelo órgão colegiado no que tange à admissibilidade e aos limites objetivos do incidente, sobretudo no que diz respeito à definição da questão jurídica e à identificação de circunstâncias fáticas que ensejaram a controvérsia e para as quais a tese será aplicada. Frise-se que é nessa decisão que o relator irá adotar as medidas para regular o processamento do incidente bem como a viabilização da legitimidade da tese jurídica, visando à efetiva divulgação da instauração do IRDR e a participação dos sujeitos envolvidos no debate. Essa decisão de organização serve para definir os limites do incidente e as diretrizes que irão orientar o seu processamento (DIDIER JR.; TEMER, 2016, p. 3). O RITJBA descreve esse passo com bastante detalhes. Didier Jr. e Cunha (2017, p. 737) elogiam o modelo de organização do incidente que o TJBA adotou, descrevendo o parágrafo $8^{\circ}$ do art. 219, inclusive, como "um excelente paradigma". A decisão que organiza o IRDR cumpre importantes funções e é essencial para:

[...] (i) identificação precisa do objeto do incidente; (ii) escolha, se necessário, dos casos representativos da controvérsia; (iii) definição de critérios para a participação de terceiros, seja como amicus curiae, seja como sujeitos juridicamente interessados, inclusive definindo uma possível calendarização do procedimento do incidente; (iv) comunicação aos interessados e à sociedade sobre afetação da matéria; (v) comunicação aos juízos inferiores sobre a suspensão das demandas que versem sobre a questão submetida a julgamento (DIDIER JR.; TEMER, 2016, p. 3).

Para além do já previsto no CPC/2015, o RITJBA, em mais uma amostragem de seu didatismo paradigmático, preceitua que a indicação precisa do objeto vai além de sua simples identificação. A decisão que organiza o incidente deverá identificar as circunstâncias fáticas que ensejam a controvérsia em torno da questão jurídica e apresentar um índice com os fundamentos, acerca da questão jurídica, apresentados até o momento da admissão do IRDR, inclusive os que constem de manifestações utilizadas para fins de instruir o pedido ou ofício de instauração, e com os dispositivos normativos relacionados à controvérsia. Observamos essas últimas providências previstas pelo RITJBA como importantes mecanismos a título de catalogação, o que pode facilitar bastante a atividade dos representantes processuais das partes que pretendam proceder o distinguishing (distinção), na possibilidade de ter o seu processo suspenso.

Desse modo, a decisão que organiza o incidente cumpre importantes funções. Como já afirmado, de início, ela serve para definir os limites do grupo a ser tutelado pela decisão do incidente. Quatro propósitos podem ser identificados a partir dessa decisão, sendo eles: a definição da questão de direito a ser decidida de modo a fixar os limites objetivos da atuação do tribunal; o estabelecimento dos critérios para a intervenção de amicus curiae e de eventuais terceiros interessados; a facilitação da identificação dos processos pendentes que deverão ter a 
tramitação suspensa; facilitar a aplicação da tese firmada nos processos futuros em que se discuta a mesma questão (DIDIEIR JR.; CUNHA, 2017, p. 738).

O $\int 9^{\circ}$ do art. 219 dispõe sobre a comunicação que deverá ser feita, após a admissão do incidente, aos órgãos jurisdicionais vinculados ao Tribunal e aos juizados especiais. Já o $\ 10$ do mesmo artigo dispõe sobre a intimação das partes dos processos suspensos por força da decisão pós admissibilidade do IRDR. A intimação das partes da maneira que está disciplinada no RITJBA se baseia no entendimento do Fórum Permanente de Processualistas Cíveis (FPPC), que em seu enunciado $n^{\circ} 348$, dispõe que os interessados serão intimados da suspensão de seus processos individuais, podendo requerer o prosseguimento ao juiz ou tribunal onde tramitarem, demonstrando a distinção entre a questão a ser decidida e aquela a ser julgada no incidente de resolução de demandas repetitivas, ou nos recursos repetitivos.

O \11 do art. 219 apenas reproduz o que já está disciplinado no art. 979 do CPC/2015, no que diz respeito à atualização do cadastro eletrônico do Tribunal para incluir informações relativas a participações de interessados na construção da tese do incidente. Já o \12 prevê que além dos cadastros referidos no art. 979 do CPC/2015, deverá o Tribunal manter os autos do incidente disponíveis para consulta pública na rede mundial de computadores. Não chega a ser uma inovação, uma vez que na era da tramitação de processos pela via eletrônica, já é possível ter acesso a quase todos os atos e peças processuais via internet. Entretanto, cabe salientar que o TJBA além de disponibilizar os autos processuais do incidente na rede mundial de computadores, também possibilita o acompanhamento das sessões em vídeo, em tempo real, também pela rede mundial de computadores. O Tribunal já conta com o sistema de streaming desde o ano de 2017, o que é uma forma que ampliar a participação dos interessados no deslinde do incidente.

Didier Jr. e Temer (2016, p.6) sustentam que os atos do IRDR deprecam por publicidade, sob a alegação, in verbis:

Embora o Código preveja a inscrição do incidente admitido nos registros do próprio tribunal e do CNJ, apenas indica as informações mínimas que devem constar do cadastro no momento posterior à fixação da tese, como os "fundamentos determinantes da decisão e os dispositivos normativos a ela relacionados” (art. 979). É necessário, contudo, que conste do cadastro as informações mencionadas na decisão de organização quanto à delimitação da questão afetada, as circunstâncias fáticas que ensejaram a controvérsia os argumento e dispositivos normativos apresentados até a admissão, e, ainda, quanto aos critérios fixados para permitir intervenções. Ademais, ainda que silente a lei, é necessário que os cadastros a que se referem o art. 979 do CPC/2015 (LGL \2015\1656) sejam constantemente atualizados, notadamente para indicar a admissão de amicus curiae e a designação de audiências públicas, conforme já preveem os regimentos internos do TRF2 e do TJBA. Por fim, é essencial que o tribunal disponibilize os autos do incidente em meio eletrônico, para consulta pública das petições e decisões proferidas, bem como que disponibilize gravação de vídeo das 
sessões e audiências públicas realizadas no IRDR, o que deverá ser regulado no regimento interno dos tribunais (DIDIER JR. e TEMER, 2016, p. 6).

Do mesmo modo que está disposto no CPC/2015, o RITJBA prevê que após concluída a instrução do incidente, o relator fará a solicitação para que seja realizada a sessão de julgamento. O art. 983, $\$ 2^{\circ}$ do CPC/20015, dispõe acerca da solicitação, por parte do relator, de data para julgar o IRDR. A lei processual é silente quanto ao lapso temporal que deverá se estabelecer entre o final da instrução e a data do julgamento do incidente. $\mathrm{O}$ art. 221, caput, do RITJBA define que a referida solicitação para dia de julgamento deverá respeitar o prazo mínimo de 20 dias entre a realização da sessão de julgamento e a publicação da pauta e inserção da informação nos cadastros referidos no art. 979 do CPC/2015.

O art. 221 do RITJBA ainda traz uma novidade acerca dos prazos a serem seguidos na tramitação do incidente. $\mathrm{O} \int 1^{\circ}$ do referido artigo possibilita que seja estabelecido um acordo entre as partes envolvidas no incidente para que possam de comum acordo, definir o calendário de instrução e julgamento, nos ternos do art. 191 do CPC/2015. A calendarização processual, possibilidade aventada pelo Código de Processo Civil em vigência, é um negócio processual plurilateral típico celebrado entre o juiz e as partes envolvidas na questão.

Essa técnica de governança judicial permite que se abandonem diversos procedimentos que são pendentes de decisões judiciais, por exemplo, a utilização de publicações sucessivas. A partir dessa técnica negocial, o término de um prazo para o autor, por exemplo, já deflagraria de modo automático o próximo passo processual do réu. Isso intenta evitar os chamados "buracos negros", lapsos temporais inúteis que só contribuem para o atraso da prestação jurisdicional (COSTA, 2015, p. 94).

Em decorrência da calendarização processual possibilitada em sede de IRDR pelo RITJBA, é possível aos sujeitos processuais anteverem provável duração da tramitação processual, afinal, além de ser um meio de acelerar o processo, a calendarização processual também serve à organização e previsibilidade do tramite do IRDR. Segundo a doutrina:

[...] O calendário pode ser muito útil para o agendamento de audiências públicas e manifestações sucessivas das partes, encurtando o tempo de duração do processamento do IRDR ou do recurso repetitivo, conferindo-lhe a prioridade imposta pela lei. Convém advertir que o calendário processual é sempre negocial; não pode ser imposto pelo órgão jurisdicional. Trata-se de um negócio jurídico processual, plurilateral, havendo necessidade de acordo de, pelo menos, três vontades: a do autor, a do réu e a do órgão julgador. Se houver intervenientes, estes também devem integrar o negócio processual que fixa o calendário. No IRDR ou recurso repetitivo, todos devem participar da celebração do calendário (DIDIER Jr e CUNHA, 2017, p. 699). 
O art. 222, caput, do RITBJA estabelece o roteiro que deve ser seguido na redação do acórdão. A redação final deverá conter elementos essenciais, quais sejam, o relatório que identifique as partes, o caso, os pedidos e o registro das principais ocorrências havidas no trâmite do incidente; a identificação das circunstâncias fáticas que ensejam a controvérsia em torno da questão jurídica que ensejou a instauração do IRDR; o índice com todos os fundamentos que sintetizaram a decisão, sejam eles favoráveis ou contrários; a análise de todos esses fundamentos; os dispositivos legais contidos na questão alvo de debate no incidente; a enunciação da tese jurídica objeto do incidente; a fundamentação para a solução do caso; o dispositivo no qual o tribunal resolverá o caso apreciado. Construir o acórdão analisando detidamente todos esses elementos é de muita importância para a aplicação da tese nos casos futuros, sobretudo num país em que o sistema de precedente judicial é bastante valorizado. Segundo a doutrina:

\footnotetext{
O relatório constitui elemento importante, sobretudo num sistema como o brasileiro, que valoriza o precedente judicial. Essa importância aumenta, ainda mais, nos acórdãos. É pelo relatório que são identificados os detalhes da causa, a fim de que se possa verificar, nos casos sucessivos, a adequação do precedente para a solução do caso, possibilitando que se conclua pela sua aplicação ou não à hipótese posta a julgamento. É relevante o relatório no acórdão, devendo dele constar para que se possa avaliar a aplicação, nos casos sucessivos, da regra nele construída (CUNHA, p. 1229).
}

$\mathrm{O} \int 1^{\circ}$ do artigo em questão ressalta que, em havendo desistência ou abandono do incidente, no texto do acórdão não haverá a necessidade de constar nem a fundamentação para a solução do caso que deu origem ao IRDR, nem mesmo o dispositivo no qual o tribunal haverá de resolver o caso. $\mathrm{O} \int 2^{\circ}$ serve à elucidação de dúvidas doutrinárias. O referido dispositivo estabelece que o IRDR suscitado por Juiz de Direito somente será admitido se houver, no Tribunal, processo de competência originária, remessa necessária ou recurso que verse sobre a questão de direito repetitiva, que será selecionado como representativo da controvérsia.

Sem muitas inovações, os arts. 223 e 224 do RITJBA apenas reproduzem disposições contidas nos CPC/2015. O art. 223 versa sobre a vinculação obrigatória da tese fixada a partir do incidente a todos os órgãos jurisdicionais de primeira e segunda instância, inclusive aos Juizados Especiais; com tal inteligência, vide art. 985 e incisos do CPC/2015. O art. 224 RITJBA dispõe sobre a irrecorribilidade do acórdão que inadmite o incidente.

O art. 225 RITJBA estabelece a prevenção do redator do acórdão, que julgou o incidente, para julgar futuros e eventuais incidentes em que se discuta a mesma questão jurídica. O referido artigo ainda faz referência a um outro dispositivo do mesmo regimento (art. 160, RITJBA), que regula a eventual substituição de Desembargador prevento dentro do TJBA. Segundo Didier Jr e Cunha (2017, p. 701), o órgão colegiado do tribunal que nos termos do seu regimento interno fixou a tese a ser rediscutida tem preferência para revisá-la. 
O último artigo do RITJBA que trata do IRDR, art. 226 e parágrafos, dispõe acerca da revisão da tese jurídica. Cabe ressaltar apenas que o dispositivo em comento e seus parágrafos regulam, basicamente, que a revisão da tese jurídica do incidente deve seguir os mesmos passos do trâmite do incidente originário, tendo em vista que, segundo a doutrina, a revisão da tese, exatamente por redundar na formação de outro precedente obrigatório, deve ocorrer após a instauração de um novo incidente de julgamento de casos repetitivos. Novo precedente obrigatório, neste caso, deve ser formado da mesma maneira pela qual o precedente foi formado (DIDIER JR.; CUNHA, 2017, p. 701).

\section{Primeiras aplicações do IRDR no âmbito do TJBA}

A partir da entrada em vigência do NCPC, em março de 2016, suscitar incidentes da natureza do IRDR tornou-se possível. No TJBA, até junho daquele mesmo ano, já haviam sido admitidos três incidentes ${ }^{5}$ por unanimidade na Seção Cível de Direito Público. Atualmente, em consulta ao banco de dados do Núcleo de Gerenciamento de Precedentes (NUGEP ${ }^{6}$ ) do TJBA, é possível encontrar o registro da interposição de, pelo menos, 12 (doze) IRDR suscitados perante o tribunal.

Em fevereiro de 2019 houve o julgamento do primeiro IRDR no âmbito do TJBA. A controvérsia suscitada no Tema 03 (os incidentes são registrados por temas numerados) versava sobre a contagem do prazo de prescrição da Gratificação de Habilitação Policial Militar (GHPM). A tese fixada a partir do julgamento é que:

A supressão da Gratificação de Habilitação Policial Militar - GHPM por meio da Lei Estadual $n^{\circ}$ 7.145-1997 constitui ato único de efeitos concretos, sujeitando-se a pretensão de restabelecimento da aludida gratificação ao prazo prescricional de 05 (cinco) anos previsto no art. $1^{\circ}$ do Decreto $\mathrm{n}^{\circ} 20.910 / 32$, a atingir o próprio fundo do direito, contados da publicação da lei. (TJBA, 2019)

Com o trânsito em julgado da decisão do Tema 03, voltaram a tramitar $525^{7}$ (quinhentos e vinte e cinco) processos que tratavam da mesma controvérsia e que se encontravam suspensos em obediência ao rito processual do processamento do incidente.

Essa decisão ainda provocou a edição da Súmula $n^{\circ} 16^{8}$ do TJBA nos seguintes termos: "Prescreve em 05 (cinco) anos, contados da data de publicação da Lei Estadual no

${ }^{5}$ http://www5.tiba.jus.br/portal/tiba-inicia-processamento-de-incidentes-de-resolucao-de-demanda-repetitiva-irdrs/ ${ }^{6} \mathrm{O}$ NUGEP foi criado em outubro de 2016 pelo TJBA em atendimento à disposição contida na Resolução n. ${ }^{\circ} 235$ do $\mathrm{CNJ}$, de 13 de julho daquele mesmo ano, que determinou a criação de um núcleo para monitorar e gerenciar processo submetidos à sistemática de Incidentes de Resolução de Demandas Repetitivas e outros de natureza semelhante. Disponível em: http://www2.tjba.jus.br/nugep/irdr/

7 http://www5.tjba.jus.br/portal/tjba-julga-pela-primeira-vez-um-incidente-de-resolucao-de-demandas-repetitivasirdr/ 
7.145/1997, a pretensão de restabelecimento da GHPM - Gratificação de Habilitação Policial Militar, a atingir o próprio fundo de direito".

Outra decisão foi proferida a partir do incidente do Tema $06^{9}$. O questionamento levantado por esse incidente versava sobre a definição de marco temporal para se aplicar ou não percentual decorrente da conversão do Cruzeiro Real em URV sobre a remuneração e proventos dos servidores públicos estaduais do Poder Executivo do Estado da Bahia, ativos e inativos, e pensionistas, analisando se as Leis Estaduais $\mathrm{n}^{\circ} 7.145 / 1997, \mathrm{n}^{\circ} 7.622 / 2000$ e $\mathrm{n}^{\circ}$ 8.889/2003 implicaram, ou não, na reestruturação das carreiras da Polícia Militar do Estado da Bahia e dos servidores públicos civis e militares da Administração Direta, das autarquias e fundações públicas.

Com a controvérsia dirimida, fixou-se a tese de que

As Leis Estaduais $n^{\circ} 7.145 / 1997, n^{\circ} 7.622 / 2000$ e $n^{\circ} 8.889 / 2003$ implicaram na reestruturação das carreiras da Polícia Militar do Estado da Bahia e dos servidores públicos civis e militares da administração direta, das autarquias e fundações, figurando como marco temporal para aplicação do percentual decorrente da equivocada conversão do Cruzeiro Real em URV sobre a remuneração e proventos dos servidores públicos estaduais do Poder Executivo estadual, ativos e inativos. (TJBA, 2019)

A partir do julgamento deste IRDR, 855 (oitocentos e cinquenta e cinco) processos que são fundados na mesma questão jurídica, voltaram a tramitar na primeira instância e aguardam solução a partir da tese fixada.

Como último exemplo, temos a decisão proferida no IRDR originário do Tema 08, que versa sobre a possibilidade de extinção sem resolução de mérito, por ausência de interesse processual, das ações de execução fiscal destinadas à cobrança de créditos tributários inferiores à quantia mínima prevista no art. 276, da Lei Municipal no 7.186/2007 (Código Tributário e de Rendas do Município de Salvador).

A partir do julgamento desse incidente, 1514 (mil quinhentos e catorze) recursos foram julgados entre janeiro e agosto de 2020, segundo o relatório ${ }^{10}$ de produtividade da $4^{\mathrm{a}}$ Câmara Cível do Poder Judiciário da Bahia, referente aos oito primeiros meses do ano.

\section{Considerações finais}

O IRDR é uma forma de responder a diversos problemas relacionados às questões repetitivas nos tribunais brasileiros, pois mesmo existindo a possibilidade de serem ajuizadas ações coletivas, as demandas repetitivas ainda persistem e multiplicam-se a cada dia. Acontece

\footnotetext{
${ }^{8}$ Súmula 16 do TJBA. Disponível em: http://www5.tjba.jus.br/portal/sumulas/

$9 \quad$ http://www5.tjba.jus.br/portal/tjba-julga-incidente-de-resolucao-de-demandas-repetitivas-de-tema-ligado-areestruturacao-das-carreiras-de-policiais-militares-e-servidores/

${ }^{10} \mathrm{http}: / /$ www5.tjba.jus.br/portal/4a-camara-civel-do-pjba-divulga-dados-de-produtividade/
} 
que, embora haja a possibilidade de ajuizamento de demandas coletivamente, muitos problemas atrelados à litigiosidade de massa ainda são solucionados em ações individuais e consequência lógica disso é que existem inúmeras demandas sobre uma mesma questão, o que, inevitavelmente, contribui para o abarrotamento do judiciário, a morosidade, a má prestação jurisdicional, a violação da isonomia processual, entre outros problemas. Daí a necessidade de incluir no ordenamento jurídico uma ferramenta processual voltada à gestão dessas demandas repetitivas de modo isonômico e imprimindo segurança jurídica à prestação jurisdicional.

A previsão legal do IRDR deixou aos tribunais a importante tarefa de instrumentalizar o procedimento do instituto em apreço por meio dos seus regimentos internos. O Regimento Interno do Tribunal de Justiça da Bahia, no que tange ao regramento do dispositivo legal de resolução demandas repetitivas, ao complementar as disposições contidas no Código de Processo Civil, constitui um excelente paradigma de como tratar didática e doutrinariamente o procedimento do IRDR.

Neste trabalho, procurou-se verificar qual o tratamento dispensado ao instituto processual objeto desta pesquisa dentro do RITJA. No transcurso deste exame foi possível constatar que a disciplina do regramento do IRDR pelo Tribunal de Justiça da Bahia dentro do seu regimento para além de seu mencionado caráter didático, é também esclarecedora e útil ao funcionamento do referido instituto que se encontra em pleno uso pela comunidade jurídica baiana. Na prática, pôde-se observar que o julgamento de IRDR e a consequente fixação de uma tese sobre uma questão controversa e massificada pode ajudar a imprimir celeridade na resolução de demandas judiciais.

\section{Referências}

$4^{a}$ Câmara Cível do PJBA divulga dados de produtividade. Disponível em: http://www5.tjba.jus.br/portal/4a-camara-civel-do-pjba-divulga-dados-de-produtividade/. Acesso em 22 nov. 2020.

ANASTÁCIO, Thiago. Regimento interno dos tribunais é lei. Disponível em: < https://www.conjur.com.br/2013-mar-29/thiago-anastacio-regimento-interno-tribunais-lei>. Acesso em: 15 fev. 2019.

BASTOS, Antônio Adonias Aguiar. Devido processo legal nas demandas repetitivas. Disponível em: <http://repositorio.ufba.br/ri/handle/ri/15817..> Acesso em: 10 mar. 2019.

BAHIA. Tribunal de Justiça do Estado da Bahia. Regimento Interno do Tribunal de Justiça do Estado da Bahia. Disponível em: <http://www5.tjba.jus.br/portal/wpcontent/uploads/2019/01/REGIMENTO-INTERNO-ATUALIZADO-EM-10012019.pdf>. Acesso em: 02 fev. 2019. 
Tribunal de Justiça do Estado da Bahia. Núcleo de Gerenciamento de Precedentes [banco de dados]. Disponível em: http://www2.tjba.jus.br/nugep/. Acesso em 22 nov. 2020.

Tribunal de Justiça do Estado da Bahia. Súmula 16. In: Súmulas. Disponível em: http://www5.tiba.jus.br/portal/sumulas/. Acesso em 22 nov. 2020.

BRASIL. Constituição Federal de 1988. Promulgada em 5 de outubro de 1988. Disponível em <http://www.planalto.gov.br/ccivil_03/constituicao/constituição.htm>. Acesso em: 15 fev. 2019

Código de Processo Civil. Lei n 5.869, de 11 de janeiro de 1973. Disponível em <www.planalto.gov.br/ccivil_03/LEIS/L5869.htm>. Acesso em 13 mar. 2019.

Código de Processo Civil e normas correlatas. 7. ed. Brasília: Senado Federal, Coordenação de Edições Técnicas, 2015. Disponível em: < https://www2.senado.leg.br/bdsf/bitstream/handle/id/512422/001041135.pdf>. Acesso em: 10 fev. 2019.

Comentários ao novo Código de Processo Civil. Rio de Janeiro: Forense, 2015.

CÂMARA, Alexandre Freitas. O novo processo civil brasileiro. 3 ed., São Paulo: Atlas, 2017.

COSTA, Eduardo José da Fonseca. Calendarização Processual. In: Revista do Ministério Público do Rio de Janeiro no 57, jul./set. 2015. Disponível em:< https://bdjur.sti.jus.br/jspui/bitstream/2011/98635/calendarizacao_processual_costa.pdf>. Acesso em 13 fev. 2019.

CUNHA, Leonardo Carneiro. “Comentários ao art. 489”. Breves comentários ao novo Código de Processo Civil. Teresa Arruda Alvim Wambier; Fredie Didier Jr.; Eduardo Talamini; Bruno Dantas (coords.). São Paulo: RT, 2015.

DIDIER JR. Fredie., CUNHA, Leonardo Carneiro da. Curso de direito processual civil. Vol. 3. 14. ed. Salvador: Juspodivm, 2017.

TEMER, Sofia. A decisão de organização do incidente de resolução de demandas repetitivas: importância, conteúdo e o papel do regimento interno do tribunal. Disponível em:< https://www.academia.edu/28460084/A_DECIS\%C3\%83O_DE_ORGANIZA\%C3\%87\%C3 $\% 83$ O_DO_INCIDENTE_DE_RESOLU $\%$ C3\%87\%C3\%83O_DE_DEMANDAS_REPETIT IVAS_IMPORT $\%$ C3\%82NCIA_CONTE $\%$ C3\%9ADO_E_O_PAPEL_DO_REGIMENTO_I NTERNO_DO_TRIBUNAL>. Acesso em: 14 fev. 2019.

FREITAS, Gabriel Artime Suzart de. Incidente de Resolução de Demandas Repetitivas: Análise comparativa dos sistemas jurídicos brasileiro e alemão. Disponível em: < http://portal.faculdadebaianadedireito.com.br/portal/monografias/Gabriel\%20Artime\%20Suzar t\%20de\%20Freitas.pdf >. Acesso em: 15 jan. 2019.

MENDES, Aluisio Gonçalves de Castro; TEMER, Sofia. O incidente de resolução de demandas repetitivas no novo Código de Processo Civil. Revista de Processo, vol.243, maio/2015, p.283331. Disponível em: http://www.tepedino.adv.br/wpp/wp-

content/uploads/2018/06/incidente_resolucao_demandas.pdf. Acesso em 26 mai. 2020 
TEMER, Sofia. Incidente de resolução de demandas repetitivas. 2. Ed, Salvador, JusPodivm, 2017.

THEODORO JÚNIOR, Humberto. Curso de Direito Processual Civil - vol. III. 5. Ed. rev., atual e ampl. Rio de Janeiro: Forense, 2017.

TJBA inicia processamento de Incidente de Resolução de Demandas Repetitivas IRDR.

Disponível em: http://www5.tjba.jus.br/portal/tjba-inicia-processamento-de-incidentes-deresolucao-de-demanda-repetitiva-irdrs/ Acesso em 22 nov. 2020.

TJBA julga pela primeira vez um Incidente de Resolução de Demandas Repetitivas. Disponível em: http://www5.tjba.jus.br/portal/tjba-julga-pela-primeira-vez-um-incidente-de-resolucao-dedemandas-repetitivas-irdr/. Acesso em 22 nov. 2020.

TJBA julga Incidente de Resolução de Demandas Repetitivas de tema ligado à reestruturação das carreiras de policiais militares e servidores. Disponível em: http://www5.tjba.jus.br/portal/tjbajulga-incidente-de-resolucao-de-demandas-repetitivas-de-tema-ligado-a-reestruturacao-dascarreiras-de-policiais-militares-e-servidores/. Acesso em 22 nov. 2020. 